\title{
Two-dimensional DNA displays for comparisons of bacterial genomes
}

\author{
Chad Malloff1,5, Edie Dullaghan²,4, Alice Li1,4, Richard Stokes 1,2,3,4, Rachel Fernandez ${ }^{3 *}$ and \\ Wan $\operatorname{Lam}^{1,5}$
}

The 'Departments of Pathology \& Laboratory Medicine, 2Pediatrics, 3Microbiology \& Immunology, University of British Columbia; 4 The Division of Infectious and Immunological Diseases, British Columbia's Children's Hospital; 5British Columbia Cancer Research Center, Vancouver, B.C. Canada.

*To whom correspondence should be addressed: Rachel C. Fernandez, Microbiology \& Immunology, University of British Columbia, \#300-6174 University Blvd., Vancouver, British Columbia, V6T 1 Z3 Canada. Phone: (604) 822-6824, Fax: (604) 822-6041, Email: rachelf@interchange.ubc.ca

Submitted: March 16, 2003; Revised: April 4, 2003; Accepted: April 1, 2003; Published: June 15, 2003

Indexing terms: genomics; DNA fingerprinting; gene transfer, horizontal; polymorphism (genetic); Bordetella, Mycobacterium, Pseudomonas.

\begin{abstract}
We have developed two whole genome-scanning techniques to aid in the discovery of polymorphisms as well as horizontally acquired genes in prokaryotic organisms. First, two-dimensional bacterial genomic display (2DBGD) was developed using restriction enzyme fragmentation to separate genomic DNA based on size, and then employing denaturing gradient gel electrophoresis (DGGE) in the second dimension to exploit differences in sequence composition. This technique was used to generate high-resolution displays that enable the direct comparison of $>800$ genomic fragments simultaneously and can be adapted for the high-throughput comparison of bacterial genomes. 2DBGDs are capable of detecting acquired and altered DNA, however, only in very closely related strains. If used to compare more distantly related strains (e.g. different species within a genus) numerous small changes (i.e. small deletions and point mutations) unrelated to the interesting phenotype, would encumber the comparison of 2DBGDs. For this reason a second method, bacterial comparative genomic hybridization (BCGH), was developed to directly compare bacterial genomes to identify gain or loss of genomic DNA. BCGH relies on performing 2DBGD on a pooled sample of genomic DNA from 2 strains to be compared and subsequently hybridizing the resulting 2DBGD blot separately with DNA from each individual strain. Unique spots (hybridization signals) represent foreign DNA. The identification of novel DNA is easily achieved by excising the DNA from a dried gel followed by subsequent cloning and sequencing. 2DBGD and BCGH thus represent novel high resolution genome scanning techniques for directly identifying altered and/or acquired DNA.
\end{abstract}

\section{INTRODUCTION}

Genomic variability between individual strains of bacteria may be small and well defined, but may cause large phenotypic changes. The number of novel phenotypes in natural and clinical isolates is inexhaustible and much time is spent determining the genotype of interesting phenotypes. Analysis and comparison of wholegenome sequence information has yielded a great deal of information regarding gene origins, putative virulence factors, and other systems for adaptation. Typically, however, only the genome of one individual species is sequenced and the

C2003. Biological Procedures Online. Published in Biological Procedures Online under license from the author(s). Copying, printing, redistribution and storage permitted. 
interpretation of that information is limited, as the DNA responsible for novel phenotypes is often not represented in the reference strain. In the few instances where multiple genomes of a given species have been sequenced, it is possible to generate a database of single nucleotide polymorphisms (snp) that may contribute to a particular phenotype (1-3). The accumulation of whole-genome sequences of every interesting isolate is not feasible, thus, new methods that have the ability to compare genomes regardless of sequence information will be required.

With sequence information available for a single representative bacterium, a DNA microarray can be produced and used to compare that organism to a number of related bacteria. This approach was first used by Behr et al. (4) to compare the sequenced $\mathrm{H} 37 \mathrm{Rv}$ strain of $M$. tuberculosis to $M$. bovis and attenuated $M$. bovis strains (BCG vaccine strains). In this way virulence differences between strains and gene regulation in a single strain can be examined. Unfortunately DNA that is unique to the test organism will not be identified since there is no target for hybridization on the array. This is perhaps the greatest disadvantage with this technique. Whole genome comparison methods such as pulse-field gel electrophoresis (PFGE) or restriction fragment length polymorphisms (RFLP) are generally not designed to detect small genetic alterations. Most are only capable of detecting large insertions and deletions. Twodimensional DNA electrophoresis (2DDE) is a technique that has the potential to detect even minute point mutations in the absence of pre-existing sequence data. It was first described by Fisher and Lerman, who used it to display the genome of an E. coli lambda lysogen in two-dimensions to identify the insertion of the $48 \mathrm{kbp}$ lambda phage (5). In brief, genomic DNA is digested with a frequent cutting restriction enzyme and the fragments are resolved based on size on a conventional agarose or polyacrylamide gel. The fragments are then separated based on sequence composition using denaturing gradient gel electrophoresis (DGGE). DGGE has been used extensively for the identification of point mutations $(6,7)$. Initially 2DDE was technically challenging and not widely used for the display of bacterial genomes. However, with recent advances in the technology, primarily the apparatus for generating reproducible $2 \mathrm{D}$ protein gels, 2DDE has been applied to a number of situations. It has been used to study microsatellite stability in human cancers $(8,9)$ and pedigrees $(10)$, to look at somatic transposition in zebrafish (11), and to perform gene-specific mutation analysis with genes such as BRCA1 (12).

\section{MATERIALS AND METHODS}

\section{Cell growth and DNA extraction}

Bordetella pertussis strain BP338 was cultured on Bordet-Gengou agar (Becton Dickinson Microbiology Systems, Franklin Lakes, NJ) supplemented with 15\% sheep's blood (RA Media, Calgary, Alberta) as described (13). Pseudomonas aeruginosa strains were grown in LB media with $30 \mu \mathrm{g} / \mu \mathrm{l}$ of gentamicin when necessary.
Cells were harvested and DNA extracted as previously described (14). Mycobacterium tuberculosis, strain $\mathrm{H} 37 \mathrm{Rv}$ was grown in $7 \mathrm{H} 9$ broth supplemented with oleic acid-albumin-dextrose complex (OADC) plus $0.05 \%$ Tween 80, harvested and the DNA extracted as previously described (15).

\section{Display of bacterial genomic DNA using two- dimensional DNA electrophoresis}

As previously described (14-16), the generation of 2D Bacterial Genomic Displays (2DBGD) is outlined in Figure 1A-F. Five hundred nanograms to 10 micrograms of genomic DNA was digested with a chosen restriction enzyme and the DNA fragments were treated with calf intestinal alkaline phosphatase for 30 minutes at $37^{\circ} \mathrm{C}$ before phenol extraction, ethanol precipitation and resuspension in TE $(10 \mathrm{mM}$ Tris $\mathrm{Hcl}, 1 \mathrm{Mm}$ EDTA pH 7.5) (Fig. 1A). 10 micrograms of DNA is used when the gel is to be used for fragment cloning in which case only $10 \%$ of the digest is dephosphorylated. The sample was radiolabeled with $10 \mu \mathrm{Ci}$ of $\gamma^{32} \mathrm{P}$ ATP using 10 units T4 polynucleotide kinase (Fig. 1A). The labeled fragments were resolved as previously described (14, 16). Briefly, samples were first separated by fragment size on a $5 \%$ non-denaturing acrylamide gel in electrophoresis buffer for 7-8 hours at 200 volts (Fig. 1B). Each gel lane was then cut and placed on top of a $6 \%$ polyacrylamide denaturing gradient gel containing an ascending gradient of formamide (10 to $40 \% \mathrm{v} / \mathrm{v}$ ) and urea $(1.8 \mathrm{M}$ to $7 \mathrm{M})$ in electrophoresis buffer (Fig. 1C). In the second dimension, parallel DGGE was performed using an ISO-DALT apparatus for 15-17 hours at 100 volts and a constant temperature of $68.5^{\circ} \mathrm{C}$ (Fig. 1D). The gels were subsequently washed, dried and exposed to film (Figs. 1E \& F).

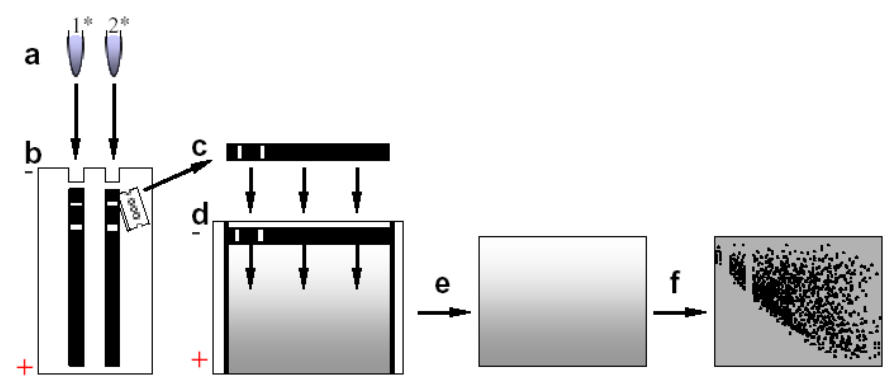

Fig. 1: Schematic outlining Two-dimensional Bacterial Genomic Display. (a) Samples to be compared are digested with the same frequent cutting enzyme(s) and radiolabelled (asterisk). (b) The fragments are then separated by size on the same first dimension polyacrylamide gel. (c) First dimension gel lanes are cut from the gel and transferred to the top of identical denaturing gradient polyacrylamide gels. (d) Sample fragments are then resolved in the second dimension based on melting characteristics. (e) The gel is then washed and dried before exposure to autoradiography film to generate an image for comparison (f).

\section{Bacterial Comparative Genomic Hybridization}

As previously described (14), Bacterial Comparative Genomic Hybridization (BCGH) is outlined in Figure 2A-G. 


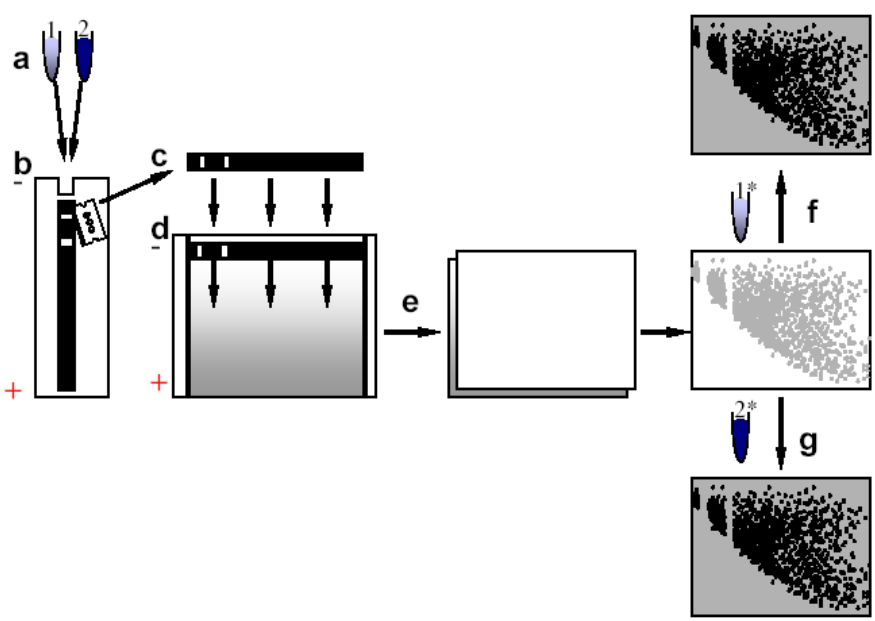

Fig. 2: Schematic outlining Bacterial Comparative Genomic Hybridization. (a) Samples to be compared are digested with the same frequent cutting enzyme(s) and combined. (b) The combined sample is then size separated on a first dimension polyacrylamide gel. (c) The first dimension gel lane is then cut from the gel and transferred to the top of a denaturing gradient polyacrylamide gel. (d) Sample fragments are then resolved in the second dimension based on melting characteristics. (e) The gel is then washed and the DNA electroblotted to a nylon membrane. (f,g) The nylon membrane is then alternatively hybridized with radiolabelled genomic DNA probe (asterisk) of generated from the comparison samples.

Strains to be compared are pooled and run on the same $2 \mathrm{D}$ gel (Fig. 2A-D). The samples are not radiolabeled. The $2 \mathrm{D}$ gel is electroblotted to a positively charged nylon membrane for 2 hours at 30 volts in a blotting apparatus that fits into the ISODALT electrophoresis system (Fig. 2E). Genomic DNA probes were synthesized from $500 \mathrm{ng}$ of digested DNA in the presence of $20 \mu \mathrm{Ci} \alpha^{32} \mathrm{P}$ CTP using random primers. Blots were hybridized with DNA from one strain (Fig. $2 \mathrm{~F}$ ) at $65^{\circ} \mathrm{C}$ for 18 hours in "Church's Buffer" (10 mg/ml bovine serum albumin; $0.5 \mathrm{mM}$ EDTA; 500 mM NaHPO 4 pH 7.2; 7\% SDS) and washed 3 times in $2 \mathrm{X} \mathrm{SSC} / 1 \% \mathrm{SDS}$ at room temperature and once in $0.2 \mathrm{X}$ SSC $/ 0.1 \%$ SDS for 15 minutes at $65^{\circ} \mathrm{C}$ and exposed to $\mathrm{x}$-ray film. The blots were then stripped of probe by boiling for 2 minutes in a solution containing $50 \mathrm{mM} \mathrm{NaPO}_{4}$ and $1 \%$ SDS and re-probed with labelled DNA from the second strain (Fig. 2G).

\section{RESULTS AND DISCUSSION}

\section{Two-dimensional Bacterial Genomic Display}

1ug of B. pertussis strain BP338 DNA was digested with Sau3A I, radiolabelled and run in two dimensions. The resulting image after exposure of the dried gel can be seen in Figure 3A. Approximately 1000 fragments can be discriminated. Similarily $500 \mathrm{ng}$ of $M$. tuberculosis H37 Rv DNA was digested with Hinf I and resolved in two dimensions (Fig. 3B). a

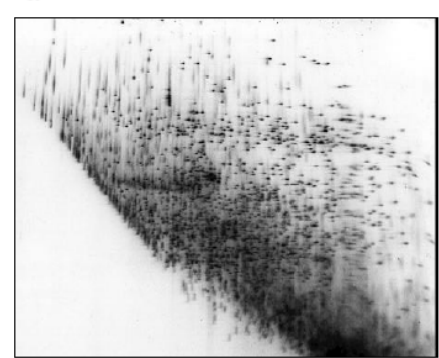

b

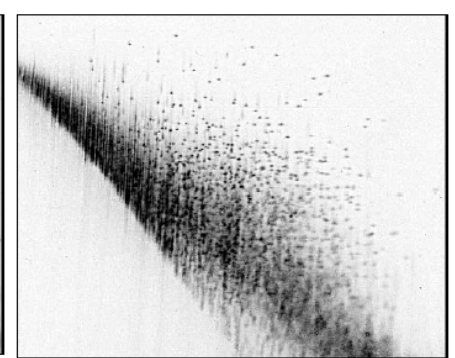

Fig. 3: Representative Two Dimensional Bacterial Genomic Displays. (a) 2DBGD of a Sau3A I digest of B. pertussis strain 338 genomic DNA. (b) 2DBGD of a Hinf $\mathrm{I}$ digest of $M$. tuberculosis strain $\mathrm{H} 37 \mathrm{Rv}$ genomic DNA.

Since the $\mathrm{G}+\mathrm{C}$ content of the $M$. tuberculosis genome is similar to that of $B$. pertussis the same separation conditions can be used. Since such a large number of loci are displayed these images can be used for large-scale comparison between bacterial strains. The use of 2DBGD to compare B. pertussis strains, or different species, strains and mutants of mycobacteria has been previously reported $(15,16)$. In these studies we showed that 2DBGD (i) is reproducible, (ii) can be used to display different fractions of the genome by changing restriction enzymes, (iii) can be used to detect large insertions that correlate to antibiotic resistance (e.g. a large Tn5-lac insertion), and small mutations (e.g. 7 point mutations within a $500 \mathrm{bp}$ fragment). Obviously, to be able to compare closely related strains and identify genetic differences a high level of reproducibility is required. This is achieved by use of the following protocol: all samples to be compared are run on the same first dimension gel and each gel lane is then transferred to parallel denaturing gradient gels that are poured as a block of multiple gels from a single solution. Gels do undergo stretching during the washing and drying process that can cause small distortions affecting comparison of the entire display at once. However when comparing local areas the spots are superimposable. To facilitate comparisons, standard software for comparing $2 \mathrm{D}$ protein gels can be used to analyze and archive 2DBGD displays.

2DBGD is a genomic fingerprinting technique that resolves bacterial genomes as hundreds of fragments. These highresolution displays enable the direct comparison of $>800$ fragments simultaneously. In this manner the identification of both small and large genetic alterations within closely related strains is achieved. This resolution also simplifies cloning and sequence analysis as fragment contamination is minimized. The cloning procedure is discussed in detail in Malloff et al. $(14,16)$.

\section{Bacterial Comparative Genomic Hybridization}

2DBGD is capable of detecting acquired DNA, however, only in very closely related strains where restriction enzyme polymorphisms are minimized. If used to compare more distantly related bacterial strains (of the same species or different species within a genus) numerous small changes (i.e. small deletions and point mutations) unrelated to the interesting phenotype would encumber the comparison of 2DBGDs. BCGH was developed to circumvent this issue. BCGH will detect DNA that is shared 
between samples and DNA that is unique to one of the comparison samples. The unique DNA represents laterally acquired DNA.

As we have previously shown (14), BCGH was performed on two isogenic strains of $P$. aeruginosa, strains H103 and H846. Strain H846 contains a $2.5-\mathrm{kb}$ cassette that contains a gene encoding resistance to the antibiotic gentamicin. This test was deemed ideal to determine the usefulness of this technique to identify acquired DNA with an associated phenotype. DNA from both strains was digested with Hinf I, pooled and subjected to 2DBGD. The display was blotted onto a single nylon membrane. This membrane was then alternatively hybridized with radiolabelled genomic probes generated from strains H103 and H846. The resulting displays can be seen in Figure 4 (17). Since the two images generated were of the same blot, the images are perfectly superimposable. DNA fragments not shared between the genomes are easily identified by excising the spot of interest, and cloning and sequencing the eluted DNA fragment $(14,16)$. In this example, the novel DNA encoded resistance to gentamicin. The Hinf I digest yields 5 new fragments unique to H846 of which only one (a predicted 623 bp fragment) was identified; presumably the other four were lost in the crowded regions of the display. This would be expected, as approximately $20 \%$ of the genome was resolved as distinct spots. This is discussed further below. Since BCGH is a hybridization-based method, only fragments that are significantly different between the comparison genomes will be noticed. Alterations such as small additions, deletions and base pair changes will not hamper the analysis since the fragments would contain enough related DNA to give a hybridization signal in both displays. This technique is therefore limited to identifying larger additions and deletions. a

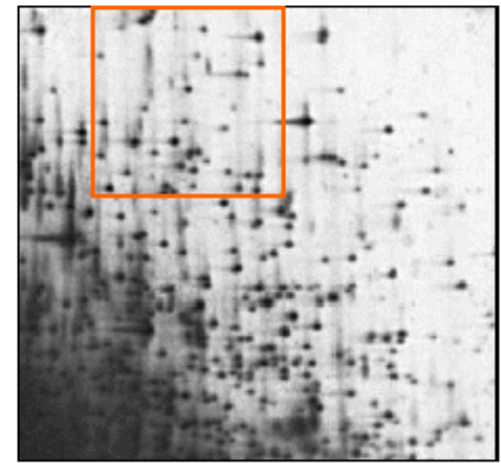

b

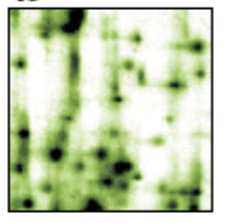

C
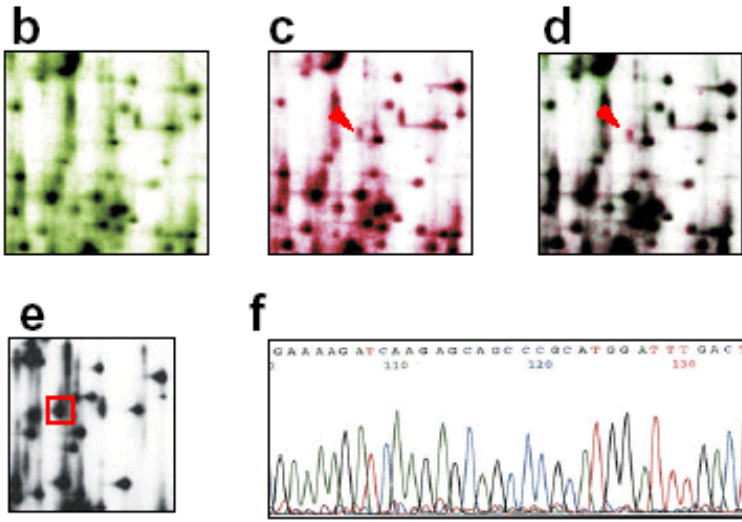

f

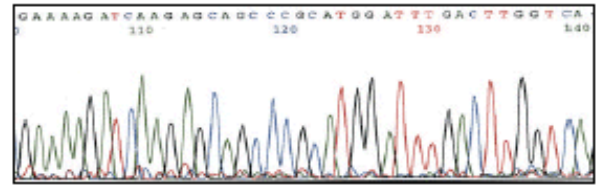

Fig. 4: Identification of acquired DNA using BCGH (17). (a) 9 X $10 \mathrm{~cm}$ area of the blot hybridized with the H846 probe is shown. The orange box represents the region displayed in ((b), (c), (d)). (b) An image from hybridization with the H103 probe was coded green. (c) An image from the H846 probe was coded red. (d) An overlay of the two displays ((b), (c)) is shown. Arrows in (c) and (d) indicate a spot that is unique to strain H846. (e), Close-up of the spot (red box) that was excised and cloned from a radiolabelled parallel gel run. Ten micrograms of radiolabeled Hinf I digested H846 DNA was resolved using 2DDE and the resulting gel was dried and exposed to film. Using the autoradiogram as a reference, the spot of interest was excised from the dried gel. Re-exposure of the gel post-excision verified that the correct spot was retrieved. The gel spot was hydrated, boiled, crushed and centrifuged. The eluted DNA was precipitated with ethanol in the presence of $10 \mu \mathrm{g}$ of glycogen as a carrier. Adaptors were ligated to the recovered DNA in a $10 \mu \mathrm{l}$ reaction volume [containing $20 \%$ of the eluted DNA, 200 units T4 DNA ligase (New England Biolabs) and 100 pmoles each of oligonucleotide 5'-CAGGCACCCGGGAGATCTGAATTC-3' and 5'ANTGAATTCAGATC-3'] for 12 hours at $16^{\circ} \mathrm{C}$, and purified with the Qiaquick PCR purification kit (Qiagen, Mississauga, Ontario). One-fifth volume of the purified DNA was amplified by PCR using the longer oligonucleotide listed above [denaturation at $94^{\circ}$ for 4 minutes followed by 35 cycles $\left(94^{\circ} 1\right.$ minute, $52^{\circ}$ 1 minute, $72^{\circ} 1$ minute)]. Gel purified PCR product was digested with EcoR I and cloned into pBlueScriptKS+ vector (Stratagene, La Jolla, CA) for sequence analysis. (f), Sequence derived from this spot. Reprinted from Journal of Molecular Biology, Volume 312, Malloff CA, Fernandez RC, Lam WL. Bacterial Comparative Genomic Hybridization: A Method for Directly Identifying Lateral Gene Transfer. Pages 1-5. Copyright (2001) with permission from Elsevier Science.

\section{Two-dimensional DNA Electrophoresis: Things to consider}

When developing the conditions for the 2DDE of bacterial genomes it was discovered that it is imperative that one starts with high quality high molecular weight genomic DNA. DNA extraction procedures that involve vortexing and extensive spins do not generate clean 2D displays. Presumably DNA that is 
sheared and nicked will result in numerous small fragments that become single stranded in the denaturing gels, clouding the displays. Therefore it is necessary to have good quality genomic DNA prior to digestion and separation in two dimensions.

Up to $20 \%$ of a genome could be resolved on a single $2 \mathrm{D}$ gel. The remaining fragments of the genome have either run off the gel or are contained in the areas of poor resolution observed at the leading edge of the gels (Fig. 3). These fragments can be resolved by altering run conditions and using alternate enzymes to generate displays. When an alternate enzyme or enzyme combination is used those fragments that are not resolved due to size or sequence composition would be located in a different position of the display. For this reason a number of suitable enzymes are selected for each organism and used to generate multiple displays for comparison. The conditions represented have been optimized for high $\mathrm{G}+\mathrm{C}$ genomes (around 65\%). Adjusting electrophoresis conditions, acrylamide concentrations, temperature and the steepness of the denaturing gradient will also allow the resolution of a different fraction of the genome (resolution of genomes with lower $\mathrm{G}+\mathrm{C}$ content can be achieved by these means). However, it is possible that a particular alteration, such as a single bp change, may not be identified with numerous displays and therefore, it is up to the examiner to determine the usefulness of 2DBGD for each particular case. Regardless, the high resolution of 2DBGD far exceeds that of other genome scanning techniques such as restriction fragment length polymorphisms (18), randomly amplified polymorphic DNA and pulse-field electrophoresis (19) that are typically used for strain typing. Those techniques lack the sensitivity to be effective in the identification of small genetic alterations. 2DDE is a powerful addition to the methodologies available for the identification of genomic changes in prokaryotic organisms and will greatly facilitate the comparison of different strains of clinical or environmental isolates.

\section{ACKNOWLEDGMENTS}

The authors would like to thank Julia Rathmann for contributions to the protocols. This work was supported by the Canadian Institutes of Health Research (grant GX-15495), the Hecht Memorial Foundation, the Network Centres of Excellence (Canadian Bacterial Diseases Network), the Florence and George Heighway Fund, and the B.C. Tuberculosis and Chest Disabled Veterans' Association. ED was the recipient of a BC Lung Association Postdoctoral Fellowship in Childhood Lung Disorders. RS is the recipient of a BC Research Institute for Children's \& Women's Health Investigatorship Award. 


\section{REFERENCES}

1. Cummings CA, Relman DA. Genomics and microbiology. Microbial forensics - "cross-examining pathogens." Science 2002; 296:1976-1979.

2. Read TD, Salzberg SL, Pop M, Shumway M, Umayam L, Jiang L, Holtzapple E, Busch JD, Smith KL, Schupp JM, Solomon D, Keim P, Fraser CM. Comparative genome sequencing for discovery of novel polymorphisms in Bacillus anthracis. Science 2002; 296:2028-2033.

3. Gutacker MM, Smoot JC, Migliaccio CA, Ricklefs SM, Hua S, Cousins DV, Graviss EA, Shashkina E, Kreiswirth BN, Musser JM. Genome-Wide Analysis of Synonymous Single Nucleotide Polymorphisms in Mycobacterium tuberculosis Complex Organisms. Resolution of genetic relationships among closely related microbial strains. Genetics 2002; 162:1533-1543.

4. Behr MA, Wilson MA, Gill WP, Salamon H, Schoolnik GK, Rane S, Small PM. Comparative genomics of BCG vaccines by whole-genome DNA microarray. Science 1999; 284:15201523.

5. Fischer SG, Lerman LS. Length-independent separation of DNA restriction fragments in two-dimensional gel electrophoresis. Cell 1979; 16:191-200.

6. Fodde R, Losekoot M. Mutation detection by denaturing gradient gel electrophoresis (DGGE). Hum Mutat 1994; 3:8394.

7. Muyzer G, Smalla K. Application of denaturing gradient gel electrophoresis (DGGE) and temperature gradient gel electrophoresis (TGGE) in microbial ecology. Antonie Van Leeuwenhoek 1998; 73:127-141.

8. Marczinek K, Hampe J, Uhlmann K, Thiel G, Barth I, Mrowka R, Vogel S, Nurnberg P. Genomic difference analysis by two-dimensional DNA fingerprinting reveals typical changes in human low-grade gliomas. Glia 1998; 23:130-138.

9. Verwest AM, de Leeuw WJ, Molijn AC, Andersen TI, Borresen AL, Mullaart E, Uitterlinden AG, Vijg J. Genome scanning of breast cancers by two-dimensional DNA typing. Br J Cancer 1994; 69:84-92.

10. Mullaart E, Verwest AM, Borglum AD, Uitterlinden AG, te Meerman GJ, Kruse TA, Vijg J. Two-dimensional DNA typing of human pedigrees: spot pattern characterization and segregation. Genomics 1995; 29:641-646.

11. Lam WL, Lee TS, Gilbert W. Active transposition in zebrafish. Proc Natl Acad Sci USA 1996; 93:10870-10875.

12. van Orsouw NJ, Dhanda RK, Elhaji Y, Narod SA, Li FP, Eng C, Vijg J. A highly accurate, low cost test for BRCA1 mutations. J Med Genet 1999; 36:747-753.

13. Fernandez RC, Weiss AA. Cloning and sequencing of a Bordetella pertussis serum resistance locus. Infect Immun 1994; 62:4727-4737.

14. Malloff CA, Fernandez RC, Lam WL. Bacterial Comparative Genomic Hybridization: A Method for Directly Identifying Lateral Gene Transfer. J Mol Biol 2001; 312:1-5.

15. Dullaghan EM, Malloff CA, Li AH, Lam WL, Stokes RW. Two-dimensional bacterial genome display: a method for the genomic analysis of mycobacteria. Microbiology 2002; 148:3111-3117.

16. Malloff CA, Fernandez RC, Dullaghan EM, Stokes RW, Lam WL. Two-dimensional display and whole genome comparison of bacterial pathogen genomes of high $\mathrm{G}+\mathrm{C}$ DNA content. Gene 2002; 293:205-211.

17. Reprinted from Journal of Molecular Biology, Volume 312, Malloff CA, Fernandez RC, Lam WL. Bacterial Comparative Genomic Hybridization: A Method for Directly Identifying Lateral Gene Transfer. Pages 1-5. Copyright (2001) with permission from Elsevier Science.

18. Cohn DL, O'Brien RJ. The use of restriction fragment length polymorphism (RFLP) analysis for epidemiological studies of tuberculosis in developing countries. Int J Tuberc Lung Dis 1998; 1:16-26.

19. Moissenet D, Valcin M, Marchand V, Grimprel E, Begue P, Garbarg-Chenon A, Vu-Thien H. Comparative DNA analysis of Bordetella pertussis clinical isolates by pulsed-field gel electrophoresis, randomly amplified polymorphism DNA, and ERIC polymerase chain reaction. FEMS Microbiol Lett 1996; 143:127-132. 


\section{PROTOCOLS}

\section{Protocol}

Some of the equipment and procedures are illustrated in Figure 5.

\section{a}

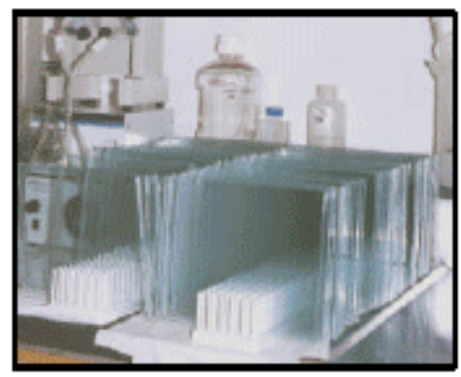

b

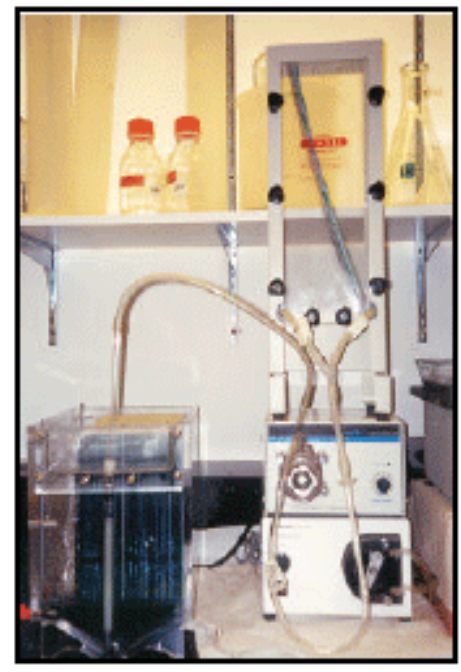

C

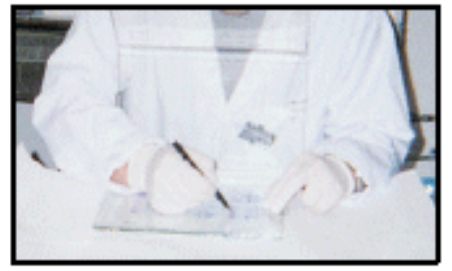

d

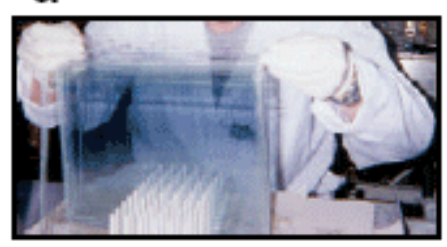

e

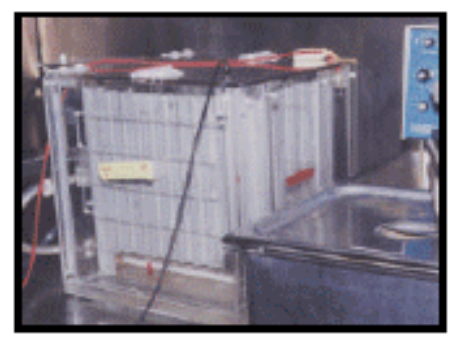

Fig. 5: Practical aspects of 2DDE. (a) Preparation of glass plates. (b) Apparatus used to simultaneously pour 24 denaturing gradient gels. (c) Preparing 1st dimension for transfer. (d) Transfer of 1D strip to 2D gel. (e) Simultaneous running of multiple gels.

\section{Equipment}

\section{Gradient Gel Casting}

Dalt Multiple Gel Caster

Dalt Gradient Maker with peristalic pump

Dalt gel cassette for $1.5 \mathrm{~mm}$ thickness (need 24 to fill caster)

\section{Second Dimension Electrophoresis Equipment}

Dalt Multiple Electrophoresis Tank with buffer circulation pump Multitemp III thermostatic circulator

Dalt Blotting Kit with rack, 5 transfer cassettes and sponges

\section{Other}

Hydrotech Gel drying system (vacuum and dryer)

PowerPac 200 power supply
Amersham

Amersham

Amersham

Amersham Amersham Amersham

Bio-Rad

Bio-Rad 
Monotech Autoradiography cassettes $14 \times 17$

VWR

Owl adjustable vertical electrophoresis system and $1 \mathrm{~mm}$ spacers

VWR

\section{Reagents}

$50 \times 2 D T A E$

Tris-base

$\mathrm{NaOAc}$ anhydrous

$\mathrm{Na} 2$ EDTA

Glacial acetic acid

Fill to $2 \mathrm{~L}$ with $\mathrm{ddH}_{2} \mathrm{O}$
$484.56 \mathrm{~g}$

$164.06 \mathrm{~g}$

$37.22 \mathrm{~g}$

$200 \mathrm{~mL}$

\section{Methods}

\section{$1 D \mathrm{Gel}$}

1. Prepare the following for a $20 \mathrm{~cm}(\mathrm{w}) \mathrm{X} 28 \mathrm{~cm}(\mathrm{~h}) \mathrm{X} 1 \mathrm{~mm}$ thick gel:

$\begin{array}{ll}\text { Acrylamide } & 4.87 \mathrm{~g} \\ \text { Bis-Acrylamide } & 0.13 \mathrm{~g} \\ \text { 2D TAE, 50X } & \underline{2 \mathrm{~mL}} \\ \text { Fill with } \mathrm{ddH}_{2} \mathrm{O} \text { to final } & 100 \mathrm{~mL}\end{array}$

\section{Pouring of $1 D \mathrm{Gel}$}

1. Clamp $1 \mathrm{~mm}$ spacers between plates with small clips, making sure spacers meet each other tightly.

2. Just prior to pouring, add $100 \mu \mathrm{l}$ TEMED to the solution and mix. Add $200 \mu \mathrm{L}$ of $20 \%$ ammonium persulfate and mix.

3. Pour PAG between glass plates and tap out air bubbles.

4. Place $\operatorname{comb}(\mathrm{s})$ in the gel.

5. Add more PAG solution if necessary.

6. Clamp the comb(s) to ensure tight fit to glass (apply clamp(s) over glass only).

7. Cover the top of the apparatus/gel with saran wrap.

8. Allow at least 2 hours to polymerize.

\section{Running of $1 D \mathrm{Gel}$}

1. Fill the chambers of running apparatus with $1 \mathrm{X} 2 \mathrm{D}$ TAE.

2. Remove the comb(s) and bottom spacer, use $\mathrm{H}_{2} \mathrm{O}$ to facilitate.

3. Cut off any excess gel and clean out the wells.

4. Place the gel in the bottom tank (angle to facilitate removal of air in the bottom space).

5. Clamp the gel plate to the stand.

6. Clamp an aluminium plate to the back of the gel plate.

7. Top up tanks with buffer.

8. Check the wells again and remove debris or air by squirting with buffer.

9. Using a pen, mark the glass to indicate the chosen wells.

10. Load the samples into the wells.

11. Attach electrodes onto the buffer chambers and plug them into the power supply.

12. Turn on the power supply and set the voltage; usually $200 \mathrm{~V}$.

13. Set the running time; usually 8 hours.

14. Load $\sim 0.5 \mu \mathrm{L} 10 \mathrm{X}$ loading dye every $\sim 2$ hours to make lanes visible for cutting.

\section{Preparation of 2D Gel Casting Chamber (Fig. 5A)}

1. Wash the gel box and 23 sets of plates (set consists of one with spacer $1.5 \mathrm{~mm}$ thick and one without). Make sure they are dry.

2. Cut and place V-shaped sponges in the groove of the gel chamber. 
3. Place Whatman paper strips in the back of the gel casting chamber.

4. Place in the first set of plates and repeat until the gel casting chamber is full.

5. Attach the front panel onto the gel casting chamber and tighten all the screws.

6. Make sure the gradient maker and tubes are clean.

\section{$2 \mathrm{CGels}$}

1. Prepare the following in $2 \mathrm{~L}$ graduated cylinders with stir bars:

\begin{tabular}{|c|c|c|}
\hline & $100 \%$ & $\underline{\mathrm{n} \%}$ \\
\hline Acrylamide & $70.1 \mathrm{~g}$ & $70.1 \mathrm{~g}$ \\
\hline Bis-Acrylamide & $1.87 \mathrm{~g}$ & $1.87 \mathrm{~g}$ \\
\hline 2D TAE, 50X & $24 \mathrm{~mL}$ & $24 \mathrm{~mL}$ \\
\hline Urea & $503 \mathrm{~g}$ & $\left(503 \mathrm{~g} \times \mathrm{n}^{\%} \%\right)$ \\
\hline Formamide & $480 \mathrm{~mL}$ & $\left(480 \mathrm{~mL} \times \mathrm{n}^{0} \%\right)$ \\
\hline Fill with $\mathrm{ddH}_{2} \mathrm{O}$ to final & $1200 \mathrm{~mL}$ & $\begin{array}{l}1200 \mathrm{~mL}+\mathrm{a} \text { few } \\
\text { crystals of bromophenol } \\
\text { blue (to help tell } \\
\text { solutions apart) }\end{array}$ \\
\hline
\end{tabular}

2. Place the solutions on stir plates and allow the solutes to completely dissolve, $\sim 5$ hours.

3. Pour the heavier solution into a side-arm flask, add the stir bar, place on a stir plate and start stirring.

4. Turn on the tap of the water aspirator, attach the vacuum tube to the flask and apply the rubber stopper to the top of the flask to degas.

5. Stir until small gas bubbles stop forming rapidly; break the vacuum before turning off the water.

6. Return the solution to the cylinder.

7. Repeat degassing procedure with the lighter solution.

8. Just prior to pouring, add $5 \mathrm{~mL}$ of $20 \%$ APS and $200 \mu \mathrm{L}$ of TEMED to each solution while stirring.

\section{Pouring 2D Gel Block (Fig. 5B)}

1. Prepare a large beaker with $\mathrm{dH}_{2} \mathrm{O}$.

2. Ensure all clamps on the tubes of the gradient maker are closed.

3. Pour the lower $\%$, blue solution in the right chamber of the gradient maker.

4. Open the right clamp.

5. Open the left clamp slowly until blue solution fills the top part of the tubing and a little into the left chamber. Close both clamps.

6. Fill the left chamber with the heavier solution.

7. Ensure the transfer tube is tightly in the gel casting chamber. Fill the side chamber of the gel casting chamber with $100 \mathrm{~mL}$ of $35 \%$ sucrose.

8. Open the bottom clamp of the gradient maker, turn the peristaltic pump just on, and quickly open the left and right clamps.

9. Turn the peristaltic pump up to level 4.

10. Periodically, shake the gel box during filling to level the gels.

11. When the blue solution is almost empty, turn the pump down.

12. Close the left clamp when the right chamber is empty (blue solution).

13. Allow the heavy solution to pump out, tilting the unit forward to obtain all of the solution.

14. Once the tubes (up to the gel box) are clear of all solution, shut off the pump and close the clamps.

15. Pull the tube out of the gel box and allow the sucrose to lift the acrylamide solutions within the gel casting chamber. Add more sucrose solution if needed.

16. Fill the gradient maker with $\mathrm{dH}_{2} \mathrm{O}$ and pump it back out. Repeat.

17. Lightly spray $0.5 \%$ SDS across the top of gels and drag a spatula through them to remove any bubbles.

18. Cover the gels with saran wrap and a glass plate. To store, add a damp paper towel under the saran wrap.

19. Rinse out cylinders, etc.

20. Let the block polymerize for at least 3 hours 


\section{Preparation Of 2D Running Tank}

Make sure to do this $\sim 4$ hours before a run

1. Remove the stands and electrodes from the tank.

2. Fill the tank with $24 \mathrm{~L}$ of $\mathrm{dH}_{2} \mathrm{O}$.

3. Add $500 \mathrm{~mL}$ of $50 \mathrm{X} 2 \mathrm{D}$ TAE and $500 \mathrm{~mL}$ more of $\mathrm{dH}_{2} \mathrm{O}$.

4. Close the lid, ensuring the electrodes are connected.

5. Plug in the circulating pump.

6. Turn on the heater of the water bath and set the desired temperature.

7. After the tank has warmed to temperature, replace the stands and electrodes and allow to warm again.

\section{Preparation of $2 \mathrm{D} \mathrm{Gels}$}

1. Remove the front of the gel casting chamber.

2. Remove the first gel and clean it off, use water to help, set aside.

3. Place the gel in a stand in the orientation it was removed.

4. Repeat until the desired number of gels have been prepared (see \#7 below).

5. Cover the remaining gels with a damp paper towel, saran wrap, and a glass plate.

6. Wash the gels off, in the sink, with $\mathrm{dH}_{2} \mathrm{O}$.

7. If not running all 10 gels (minimum of 6 gels total), place some blanks in the tank so they can start to equilibrate.

\section{Loading $1 D$ strips into $2 D$ gels (Figs. $5 C \& D$ )}

1. Prepare $1.5 \%$ agarose $/ 2 \mathrm{D}$ TAE for sealing the gels:

$\begin{array}{ll}\text { Agarose } & 3 \mathrm{~g} \\ \text { 2D TAE, 50 X } & \frac{4 \mathrm{~mL}}{200 \mathrm{~mL}} \\ \text { Fill with ddH } \mathrm{H}_{2} \mathrm{O} \text { to final } & 20\end{array}$

2. Dissolve the agarose by heating and store it in a $65^{\circ} \mathrm{C}$ water bath until needed.

3. Fill the top of the gel(s) with $1 \mathrm{X} 2 \mathrm{D}$ TAE for loading the 1D strip(s).

4. Cut the $1 \mathrm{D}$ gel to a length of $23 \mathrm{~cm}$ and lift it with a ruler.

5. Cut the $1 \mathrm{D}$ gel lane and lift it with a thin plastic ruler.

6. Drop the strip on top of the 2D gel with the high MW bands on the right (remember orientation).

7. Aspirate the buffer from the top of gel and make sure the strip is flat on the $2 \mathrm{D}$ gel.

8. Use a pipette to overlay the $1 \mathrm{D}$ strip with the $1.5 \%$ agarose. Be sure to avoid any air bubbles that will reduce current through parts of the gel.

\section{Starting 2D Gel Run (Fig. 5E)}

1. Once the agarose has solidified, place the gels into the chamber in the stand (6 gels minimum to achieve a good amperage and running temperature).

2. Make sure the gels are running to the red electrode.

3. Ensure the buffer volume is $1 \mathrm{~cm}$ below the exposed edge of the glass plates.

4. Close the lid on the tank and let the chamber equilibrate and get back up to temp. $\sim 10-20$ minutes.

5. When equilibrated, attach the electrodes to the power supply.

6. Turn on the power supply and set voltage to $100 \mathrm{~V}$.

7. Check the amps. They should be $\sim 1.3$ to 1.4 for 10 gels, $\sim 1$ for 6 gels.

8. Set the timer to the desired run time.

\section{Disassembling and Drying Gels}

1. Once the gels have finished running, turn off the water bath and power supply and unplug the circulating pump.

2. Remove the gels.

3. Place the gel into a glass or plastic dish (one per dish).

4. Pour $1 \mathrm{X} 2 \mathrm{D}$ TAE into the dish to immerse the gel. 
5. Using a spatula, crack the seal between the top plate and gel and remove the top plate.

6. Remove the agarose and $1 \mathrm{D}$ gel strips (throw in appropriate trash).

7. Rock the lower plate back and forth within the buffer to loosen the gel from the plate (this allows expansion of the gel as it hydrates).

8. Allow the gels to soak for $\sim 45$ minutes, rocking the dishes every 15 minutes to wash away the formamide and urea.

9. Realign the gel to the plate and remove them from the buffer.

10. Drain the liquid from the gel.

11. Place a piece of Whatman paper $(\sim 21 \mathrm{~cm} \times 27 \mathrm{~cm})$ over the gel.

12. Replace the top glass plate and flip over.

13. Fold a $46 \mathrm{~cm} \times 57 \mathrm{~cm}$ piece of Whatman paper in half length-wise.

14. Remove the top plate and cover the gels with plastic wrap.

15. Smooth out any bubbles.

16. Transfer to a gel drier with another piece of Whatman on it, plastic wrap side up.

17. Place a $23 \mathrm{~cm} \times 29 \mathrm{~cm}$ piece of Whatman over the plastic wrap to prevent gel dryer gasket sticking.

18. Finish assembling the gel drier.

19. Turn on the gel drier (turn on the suction for a few seconds before opening the valve).

20. Ensure suction has been established.

21. Dry the gels for $\sim 1$ hour at $80^{\circ} \mathrm{C}$.

22. Turn off the gel drier and pump.

23. Transfer the plastic wrap / gel / Whatman (single piece) sandwich to a cassette and expose to film. 